\title{
Estimation of the aerosol radiative forcing at ground level, over land, and in cloudless atmosphere, from METEOSAT-7 observation: method and case study
}

\author{
T. Elias ${ }^{1}$ and J.-L. Roujean ${ }^{2}$ \\ ${ }^{1}$ LMD, Ecole Polytechnique, 91128 Palaiseau cedex, France \\ ${ }^{2}$ CNRM/GMME/MATIS, Meteo-France, 42, avenue G. Coriolis, 31057 Toulouse cedex, France \\ Received: 1 August 2007 - Published in Atmos. Chem. Phys. Discuss.: 14 September 2007 \\ Revised: 26 November 2007 - Accepted: 17 December 2007 - Published: 8 February 2008
}

\begin{abstract}
A new method is proposed to estimate the spatial and temporal variability of the solar radiative flux reaching the surface over land (DSSF), as well as the Aerosol Radiative Forcing (ARF), in cloud-free atmosphere. The objective of regional applications of the method is attainable by using the visible broadband of METEOSAT-7 satellite instrument which scans Europe and Africa on a half-hourly basis. The method relies on a selection of best correspondence between METEOSAT-7 radiance and radiative transfer computations.

The validation of DSSF is performed comparing retrievals with ground-based measurements acquired in two contrasted environments: an urban site near Paris and a continental background site located South East of France. The study is concentrated on aerosol episodes occurring around the 2003 summer heat wave, providing 42 cases of comparison for variable solar zenith angle (from $59^{\circ}$ to $69^{\circ}$ ), variable aerosol type (biomass burning emissions and urban pollution), and variable aerosol optical thickness (a factor 6 in magnitude). The method reproduces measurements of DSSF within an accuracy assessment of $20 \mathrm{~W} \mathrm{~m}^{-2}$ (5\% in relative) in $70 \%$ of the situations, and within $40 \mathrm{~W} \mathrm{~m}^{-2}$ in $90 \%$ of the situations, for the two case studies considered here.

Considering aerosol is the main contributor in changing the measured radiance at the top of the atmosphere, DSSF temporal variability is assumed to be caused only by aerosols, and consequently ARF at ground level and over land is also retrieved: ARF is computed as the difference between DSSF and a parameterised aerosol-free reference level. Retrievals are linearly correlated with the groundbased measurements of the aerosol optical thickness (AOT): sensitivity is included between 120 and $160 \mathrm{~W} \mathrm{~m}^{-2}$ per unity of AOT at $440 \mathrm{~nm}$. AOT being an instantaneous measure in-
\end{abstract}

Correspondence to: T. Elias

(thierry.elias@1md.polytechnique.fr) dicative of the aerosol columnar amount, we prove the feasibility to infer instantaneous aerosol radiative impact at the ground level over land with METEOSAT-7 visible channel.

\section{Introduction}

Incoming solar radiation at the bottom of the atmosphere (called DSSF for Downwelling Surface Solar radiative Flux) is steering major processes of the surface-atmosphere interface such as surface heating, evaporation rate, and plant growth. DSSF is strongly dependent on the composition of the atmosphere since its elements enact absorption and scattering back to space of part of the solar radiation. Indeed molecules scatter radiation according to the Rayleigh theory, and some molecules such as water vapour absorb radiation. Moreover scattering and absorbing properties of suspended particles, which are aerosols and cloud droplets, depend on their number, size, chemical composition, and shape. Spatial and temporal heterogeneity of cloud, aerosol and water vapour fields induce the high variability of DSSF. The survey of DSSF variability was early recognised as an essential duty in meteorology and networks of ground-based pyranometer instruments were deployed to quantify the available solar energy at the ground level. However a large number of geographic areas remained poorly sampled. Then spatial remote sensing technology developed with promises of global consistent geographic coverage of the planet. An overview of the methods of satellite-based estimations of DSSF is given by Schmetz (1989) and Yu et al. (2006).

A clear understanding of the causes of the current climate change is jeopardized by the prevalent uncertainty on the role of aerosols on DSSF and on the Earth's albedo (IPCC, 2007). This is due to incomplete representation of key processes in

Published by Copernicus Publications on behalf of the European Geosciences Union. 
simulating aerosol flux emission, deposition, and transformation in the atmosphere, as well as of their radiative impacts. Resolving this issue requires to link observations of changes in the atmosphere composition to observations of change in the radiative budget. In this context, remote sensing from satellite platforms is the only way to survey the high spatial heterogeneity of aerosol properties. However it is difficult to discriminate, in the ascending signal, between the competitive contributions of 1) the radiation back-scattering by aerosols and 2) the surface reflection. Several methods have been proposed to improve the precision on the Aerosol Radiative Forcing (ARF) estimated at ground level and at the Top Of the Atmosphere (TOA).

The only approach referred by IPCC in 2001 for providing global estimates of ARF at TOA lies on the Global Circulation Modelling. Later, Yu et al. (2006) offer a review of most recent studies, on the behalf that "it is now feasible to shift the estimates of aerosol forcing from largely model-based to increasingly measurement-based". For example Zhou et al. (2005) derive ARF at both TOA and ground levels for main worldwide aerosol types using AERONET retrieved aerosol models. Even if some aspects of the aerosol parameters as the aerosol vertical profile have to be assumed, this is the most precise method to evaluate the aerosol radiative effect at ground level. However AERONET can not ensure a global coverage. Chung et al. (2005) combine three data sets to estimate ARF at surface and at TOA: i) AERONET network measurements; ii) MODIS satellite observation; iii) the GOCART chemistry-transport model. The drawback of such approach is the difficulty in guaranteeing the compatibility of the three sets of hypotheses. Yu et al. (2006) advocate exhaustive sampling of the angular, spectral and polarising properties of upwelling radiation for increasing the precision of ARF over land. However such data set is acquired only once a day and diurnal variations of both the aerosol loads and the cloud cover stay unknown.

The high frequency of the observations from the meteorological geostationary platforms avoids making hypothesis on the diurnal cycle of aerosols and clouds. Several studies prove the feasibility to provide global estimate of ARF based on the wealth of data provided by the METEOSAT instrument series. For example, Costa and Silva (2005) provide aerosol optical thickness and aerosol radiative forcing at TOA, processing the data set acquired over land from the METEOSAT Second Generation instruments, exploiting the enhanced spectral capabilities. Unfortunately their method can not be reported on the archive database acquired during the end of the 20th century by the 1 st generation instruments. Thieuleux et al. (2005) also process data sets from the new generation instruments to derive an aerosol product, but for ocean pixels.

The method we developed is innovative because four valuable characteristics are gathered in only one product: radiative impact 1) of aerosols; 2) instantaneous; 3) over land; 4) at ground level. The method provides an estimate of
DSSF in cloud-free sky and over land, by using the unique data set acquired in the solar spectrum broadband channel by the instrument onboard the METEOSAT-7 satellite, belonging to the first instrument generation mounted on meteorological geostationary spatial platforms. The high frequency of METEOSAT-7 observation allows estimating the temporal variability of DSSF, and in particular the contribution of aerosols in this variability: the difference between DSSF result and a computed aerosol-free reference provides ARF. The principle of the method lies on the energy conversion of measured TOA reflectance into surface radiative flux, through a Look Up Table generated with the $6 \mathrm{~S}$ radiative transfer code (Vermote et al., 1997), and following a sequential procedure to discern aerosol from surface signatures, based on analysis of the angular dependence of the TOA signal. The method has been developed in the context of the operational FP6/geoland project which aims the global retrieval of DSSF. Technical description is given by Elias and Roujean (2006). This paper shows results of DSSF and ARF over two predetermined sites. Section 2 presents a sensitivity study of DSSF, computed with a radiative transfer code. Section 3 presents the method and first results are compared to ground-based measurements in Sect. 4, for validation purposes of the satellite-based estimates of DSSF and ARF.

\section{Downwelling Surface Solar radiative Flux}

The Downwelling Surface Solar radiative Flux (DSSF) is the component of the solar radiation reaching the Earth's surface. DSSF is composed of: i) the transmitted solar radiation; ii) the radiation scattered by the atmosphere; and iii) the radiation reflected by the surface and back-scattered downwards by the atmosphere. DSSF is the spectral integration of the downwelling flux over the solar spectral interval $(0.3 \mu \mathrm{m}$; $4 \mu \mathrm{m})$ and is counted in units of $\mathrm{W} \mathrm{m}^{-2}$.

The main factors affecting DSSF were early clearly identified: e.g. Schmetz (1989) notes that "clouds are the strongest modulators of the shortwave radiation fields", together with the sensitivity to the solar zenith angle (SZA). From this statement, operational methods focussed on cloud radiative effects in the objective to infer continuous fields of DSSF from geostationary satellite measurements, neglecting aerosol impacts. In cloud-free sky conditions though, DSSF is most sensitive to the aerosols as it is showed by computations with the $6 \mathrm{~S}$ radiative transfer code (Vermote et al., 1997), by varying the aerosol optical properties which are the optical thickness (AOT), that is proportional to the aerosol column concentration; the single scattering albedo (ASSA) which describes the radiation absorbing property; and the Ångström exponent (AE), which depends on the size distribution respecting the Junge law. Figure 1 shows the sensitivity of DSSF to AOT at $550 \mathrm{~nm}$ (AOT550) for two values of ASSA, two values of $\mathrm{AE}$, and for $\mathrm{SZA}=30^{\circ}$ (Fig. 1a) and for $\mathrm{SZA}=60^{\circ}$ (Fig. 1b). Figure 1 outlines the decrease of 

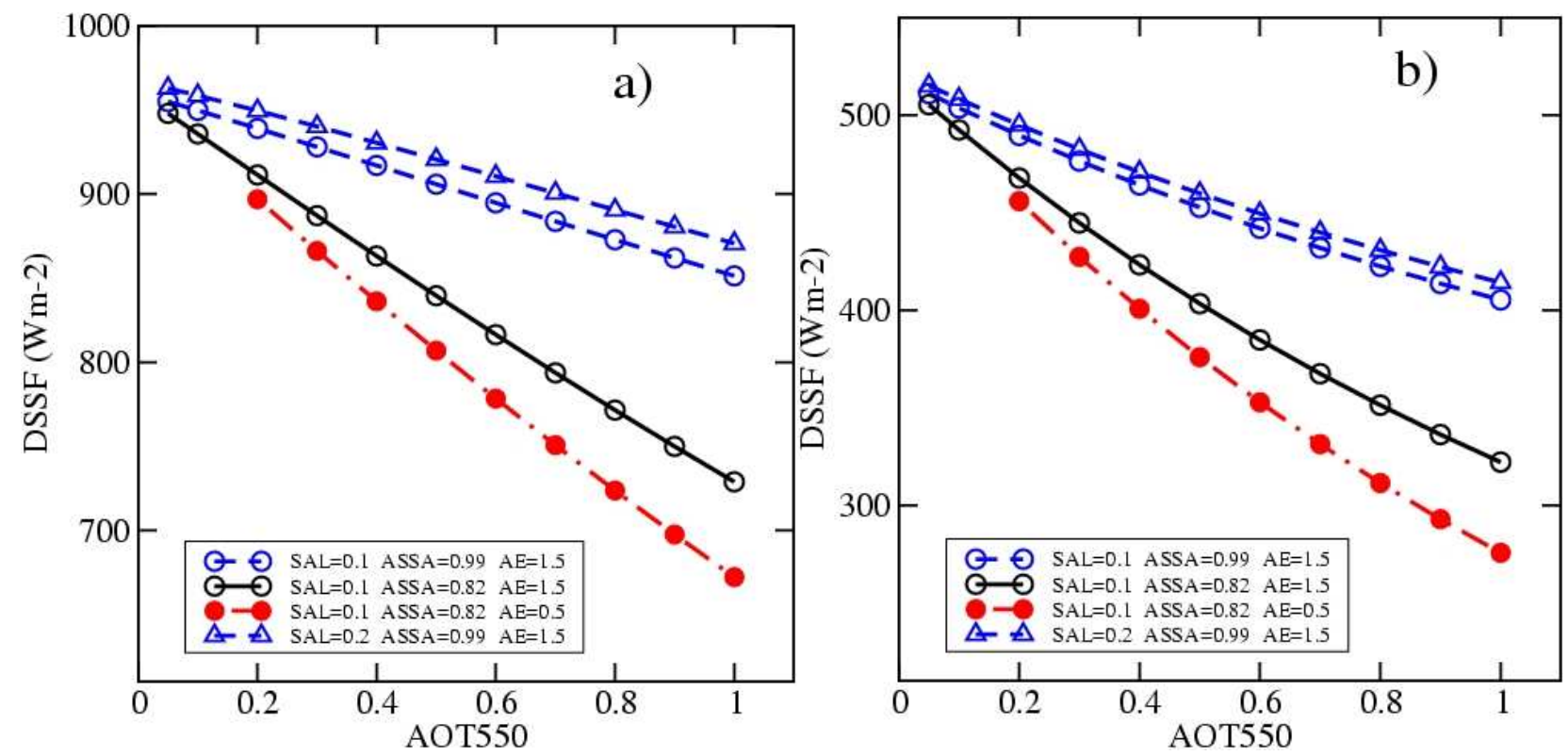

Fig. 1. Sensitivity of DSSF to the Aerosol Optical Thickness (AOT) for two values of the Aerosol Single Scattering Albedo (ASSA), two values of the Ånsgröm Exponent (AE) and two values of the Surface Albedo (SAL). Simulations are made with the $6 \mathrm{~S}$ code for (a) SZA=30 and (b) $\mathrm{SZA}=60^{\circ}$.

DSSF when AOT550 increases. The decrease is modulated by both values of ASSA and AE. For SZA $=60^{\circ}$, according to ASSA and AE, DSSF is reduced by 100 to $230 \mathrm{~W} \mathrm{~m}^{-2}$ per unity of AOT550, which represents between $20 \%$ and $45 \%$ of the aerosol-free level. For $\mathrm{SZA}=30^{\circ}$, the decrease can be larger in absolute value, reaching $300 \mathrm{~W} \mathrm{~m}^{-2}$, but is not exceeding $30 \%$ of the aerosol-free level. Surface albedo (SAL) shows little influence on DSSF as its contribution necessitates multiple scattering. Other computations are made varying successively water vapour and ozone concentrations, keeping constant other parameters, and for an aerosol-free atmosphere (not shown): the DSSF sensitivity is smaller than $1 \%$ per 100 Dobson Units (DU) of ozone and is around 2\% per $\mathrm{gcm}^{-2}$ of water vapour.

An aerosol-free reference can be simply estimated by taking up the parameterisation approach. For example, the clear-sky algorithm in the Ocean\&Sea Ice SAF project, implemented by Gautier et al. (1980) according to the method of Lacis and Hansen (1974), is formulated as follows:

$\mathrm{DSSF}_{\mathrm{par}}=\mathrm{K}_{\mathrm{esd}} \mathrm{E}_{\text {Sun }} \mu_{\mathrm{S}} \mathrm{T}$

$E_{S u n}$ is the extra terrestrial solar irradiance over the wavelength range $(0.3 \mu \mathrm{m}, 4 \mu \mathrm{m}), K_{\text {esd }}$ is the correction factor for the varying distance between Earth and sun, and $\mu_{\mathrm{S}}$ is the cosine of the solar zenith angle. Aerosols, water vapour and ozone are taken into account for calculating the downwelling atmospheric transmittance T (Appendix A). DSSF culated for an aerosol-free atmosphere $(\delta=0)$ where gaseous absorption is defined by ozone concentration of $300 \mathrm{DU}$ and water vapour concentration of $2 \mathrm{gcm}^{-2}$, and is plotted in function of SZA in Fig. 2. Difference between the 6S radiative transfer code and the parameterization is negligible for purely Rayleigh atmosphere.

Aerosol Radiative Forcing (ARF) for $\mathrm{SZA}=60^{\circ}$ is calculated by subtracting $6 \mathrm{~S}$-computed DSSF to the parameterised aerosol-free reference level and is plotted in Fig. 3 in function of AOT440. ARF is highly dependent on the aerosol optical properties. The dependence to AOT is closely linear, with a slope varying between $80 \mathrm{~W} \mathrm{~m}^{-2}$, for an accumulationmode dominated and non-absorbent aerosol population and $200 \mathrm{~W} \mathrm{~m}^{-2}$, for a coarse-mode dominated and absorbent aerosol population. The slope is also named the Aerosol Radiative Forcing Efficiency (ARFE).

\section{The method}

\subsection{Principle}

Radiative processes inside the Surface-Atmosphere System (SAS) can not be resolved by analysing a single measurement: realistic radiative transfer computation of DSSF can not be made considering METEOSAT-7 as unique source of information. Consequently the principle of our method lies on an energetical conversion from the METEOSAT-7 measurement (written UTVR $\mathrm{Reas}_{\text {for }}$ for measured Upwelling TOA Visible Radiance) to the DSSF result (written as DSSF $_{\text {res }}$ ), 


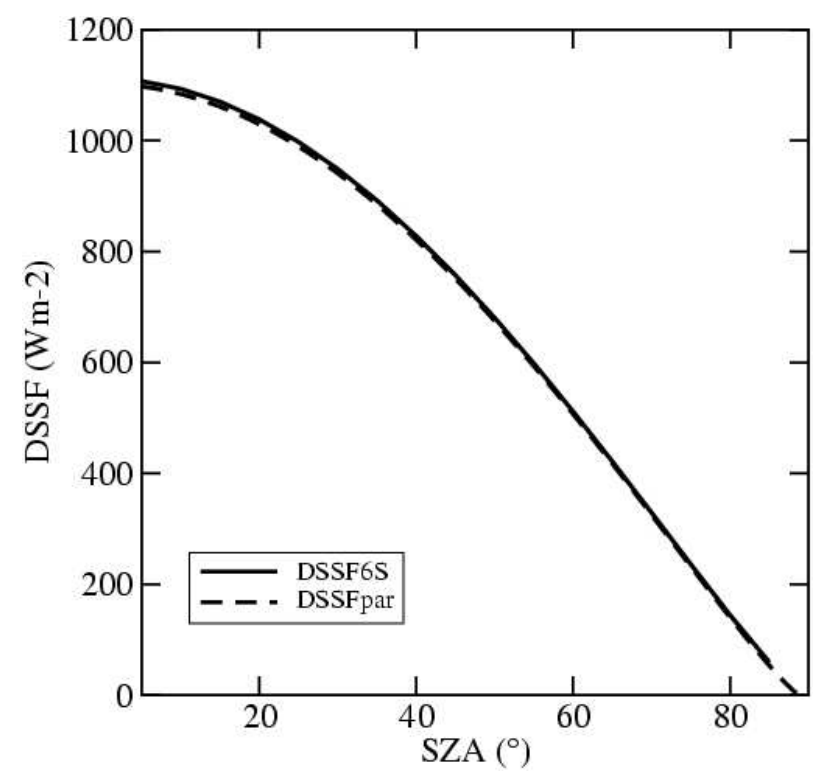

Fig. 2. Dependence of DSSF to the Solar Zenith Angle (SZA). $6 \mathrm{~S}$ simulation and parameterisation for an aerosol-free atmosphere with $300 \mathrm{DU}$ of ozone and $2 \mathrm{~g} \mathrm{~cm}^{-2}$ of water vapour.

ignoring the exact description of the SAS generating both values of METEOSAT-7 measurement and DSSF res. $_{\text {. }}$.

The core of the problem consists in establishing a universal relationship between $\mathrm{UTVR}_{\text {meas }}$ and $\mathrm{DSSF}_{\text {res }}$. Empirical methods were early proposed (see review by Schmetz, 1989), however the spatial scale of applicability is limited as the training data set can not represent the wide number of contrasted situations occurring worldwide. The alternative method, which is chosen in this study, is to generate a Look Up Table (LUT) of DSSF and UTVR values, spanning numerous realistic SAS models as input of a numerical radiative transfer code. The definition of DSSF res $_{\text {from the LUT is }}$ not trivial as several SAS models are candidate to reproduce the unique value of $\mathrm{UTVR}_{\text {meas }}$, which all generate different values of DSSF. Constrains are necessary to reduce the number of candidate SAS models and consequently to reduce the range of values of candidate DSSF.

It is noticed that dependence of UTVR on SAL increases with decreasing SZA and oppositely dependence of UTVR on AOT increases with increasing SZA. Then, the high frequency of the METEOSAT-7 measurements is exploited to discriminate between the aerosol and surface contributions to $\mathrm{UTVR}_{\text {meas }}$ : measurements made at minimum value of SZA (local noon) are devoted to operate a restitution of SAL; in counterpart, off-nadir measurements are intended to document AOT. The treatment process is then sequenced: step 1) noon measurements provide indication on the surface optical properties (SAL), which is, step 2), reported on all measurements to get information on AOT; step 3) AOT and $\mathrm{UTVR}_{\text {meas }}$ are two constraints for selecting the candi-

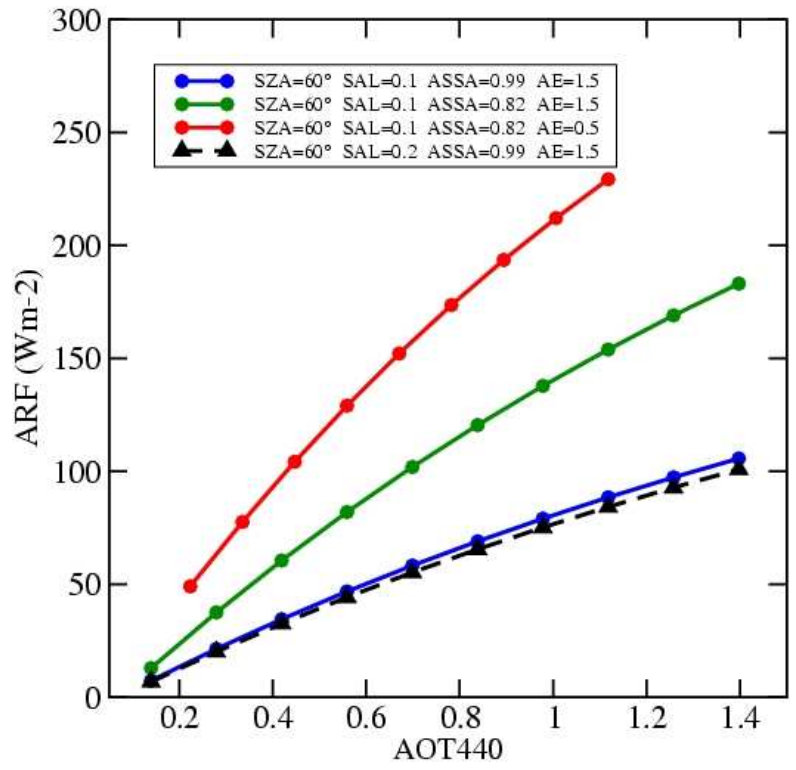

Fig. 3. Sensitivity of ARF to AOT440. ARF is computed with the $6 \mathrm{~S}$ radiative transfer code for several aerosol models, and two values of the Surface Albedo (SAL).

date SAS models; 4) DSSF is calculated for the candidate SAS models; 5) candidate DSSF values are averaged to give $\mathrm{DSSF}_{\text {res. }}$ Assuming the surface properties are stationary on a monthly basis, then all measurements made at noon during the month are first analysed to derive one monthly value of SAL, which is then reported to analyse all other measurements to infer instantaneous DSSF ${ }_{\text {res. }}$. The description of the algorithm is shared out between Sect. 3.2, for the LUT generation, and Sect. 3.3, for looking for the best correspondence between $\mathrm{UTVR}_{\text {meas }}$ and $\mathrm{DSSF}_{\text {res }}$.

\subsection{Generation of the LUT}

LUT of both values of DSSF LUT $_{\text {and }}$ UTVR $\mathrm{LUT}_{\text {in }}$ is generated with the $6 \mathrm{~S}$ radiative transfer code by varying input parameters, which describe both the SAS models and the geometry.

\subsubsection{The Surface Atmosphere Systems models}

The SAS models are defined by varying 4 parameters (Table 1). Surface reflection is represented by its albedo SAL. The aerosol is represented by three parameters describing extinction (AOT), absorption (ASSA or the Imaginary Refractive Index IRI) and the averaged particle size (AE or the Aerosol Size Distribution slope ASD). ASD is the slope of the size distribution respecting the Junge law, proportional to the Ångström exponent AE. 6S radiative transfer computations are made for each SAS model, each delivering one value of DSSF $_{\text {LUT }}$ and one value of UTVR $_{\text {LUT }}$ for one observation geometry. 
Table 1. Range of values and increments of the geophysical input parameters of the 6S radiative transfer code, describing the SAS models, and varying for generating the LUT.

\begin{tabular}{lcccc}
\hline quantity & Acronym & range & increment & $\begin{array}{c}\text { Number } \\
\text { of values }\end{array}$ \\
\hline $\begin{array}{l}\text { Surface } \\
\text { albedo }\end{array}$ & SAL & $0.05-0.40$ & 0.05 & 8 \\
$\begin{array}{l}\text { Aerosol optical } \\
\text { thickness }\end{array}$ & AOT & $0.05-1.50$ & 0.1 from 0.10 to 1.50 & 16 \\
$\begin{array}{l}\text { Aerosol size } \\
\text { distribution }\end{array}$ & ASD & $3.50,4.75$ & $/$ & 2 \\
$\begin{array}{l}\text { Aerosol } \\
\text { absorption }\end{array}$ & IRI & $0.001-0.030$ & 0.014 and 0.015 & 3 \\
\hline
\end{tabular}

As is summarised in Table 1, SAL varies between 0.05 and 0.40 with an increment of 0.05 . SAL is spectrally defined over the METEOSAT-7 visible channel. AOT is defined at $550 \mathrm{~nm}$, it varies between 0.05 and 1.50 with an increment of 0.10 from 0.10 to 1.50 and a first increment of 0.05 . This AOT interval includes most conditions observed worldwide (Holben et al., 2001). ASD takes both values of 3.50 and 4.75, and IRI the three values of $0.001,0.015$ and 0.030 . All combinations of the geophysical input parameters deliver 768 SAS models $(8 \times 16 \times 2 \times 3)$. However some combinations are not realistic. Coarse-mode dominant particles are not absorbent when they are few, because they represent maritime particles. Coarse-mode dominant particles are always absorbent when they are many since they represent desert dust particles. These characteristics are translated by these 2 conditions, respectively: 1) $\mathrm{IRI}=0.001$ when $\mathrm{ASD}=3.50$ and $\mathrm{AOT} \leq 0.20 ; 2$ ) $\mathrm{IRI} \geq 0.015$ when $\mathrm{ASD}=4.75$ and $\mathrm{AOT} \geq 0.20$. No conditions are imposed when $\mathrm{ASD}=4.75$. The final number of SAS models is 632 .

Water vapour and ozone concentrations are kept constant. For vertical profiles of pressure, temperature, ozone and water vapour concentrations, the US62 standard atmosphere (Mc Clatchey et al., 1971) implemented in the 6S code is used. The aerosol profile is exponential with a scale height of $2 \mathrm{~km}$.

\subsubsection{The geometry}

The FP6/geoland LUT considers all possible observation geometries, given a spatial geostationary platform: all pixels over the METEOSAT-7 disk, and all time of the day during a full year. The observation geometry consists in the combination of viewing and solar angles. A $1^{\circ}$-resolution in viewing and solar angles is required. The $6 \mathrm{~S}$ code is run to provide a $10^{\circ}$-resolution and polynomial interpolation of DSSF LUT $_{\text {and UTVR }}$ LUT provides the $1^{\circ}$-resolution (Elias and Roujean, 2006). The complete LUT is not necessary for the present study, and 6S computations are operated for the exact geometrical configuration corresponding to the two pixels covering the Baseline Surface Radiation Network (BSRN) stations of Carpentras $\left(44^{\circ} 03^{\prime} \mathrm{N}, 05^{\circ} 02^{\prime} \mathrm{E}\right.$, $100 \mathrm{~m}$ a.s.1.) and Palaiseau ( $48^{\circ} 42^{\prime} \mathrm{N}, 02^{\circ} 12^{\prime} \mathrm{E}, 156 \mathrm{~m}$ a.s.1.), once per day during more than a month.

\subsubsection{The altitude and the spectral domain}

The surface elevation affects DSSF $_{\text {LUT }}$ and UTVR $_{\text {LUT }}$ mainly by changing the Rayleigh scattering. All operations previously described are repeated, in the FP6/geoland algorithm, at several altitude levels, which are chosen after a statistical study of the surface altitude over continents and a sensitivity study of DSSF res (Elias and Roujean, 2006). For the paper, computations are made at the unique altitude of $300 \mathrm{~m}$ above sea level (a.s.1.), which corresponds to the lowest surface elevation range of the FP6/geoland algorithm, and which is close to the altitudes of both Carpentras and Palaiseau stations.

DSSF $_{L U T}$ and UTVR LUT $_{\text {also depend on the spectral do- }}$ main of computation. The spectral function for the computation of DSSFLUT is defined constant all over the globe according to FP6/geoland specifications, while it varies according to the spatial instrument for $U_{T V R}$ LUT. For the paper, computations of UTVR $\mathrm{LUT}_{\text {Tre made for the METEOSAT-7 }}$ spectral channel.

\subsection{Selecting DSSF $_{\text {res }}$ from the LUT}

The following step of the method consists in deriving $\mathrm{DSSF}_{\text {res }}$ using the LUT and UTVR $\mathrm{Umeas}_{\text {m }} \mathrm{UTVR}_{\text {meas }}$ is used to select the candidate SAS models which then provide an inter-

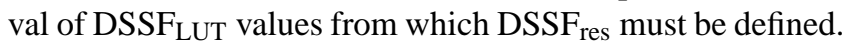
The systematic criterion of selection is called $\mathrm{UTVR}_{\text {meas }}$ cond: $\left|U_{T V R} \mathrm{LUT}_{-}-\mathrm{UTVR}_{\text {meas }}\right|<10 \%$. More criteria are applied to determine $\mathrm{DSSF}_{\text {res }}$, according to the time of acquisition of $\mathrm{UTVR}_{\text {meas }}($ Table 2).

First, information on the surface reflection properties is attained by analysing the candidate SAS models corresponding to the noon measurement. The most frequent value among 


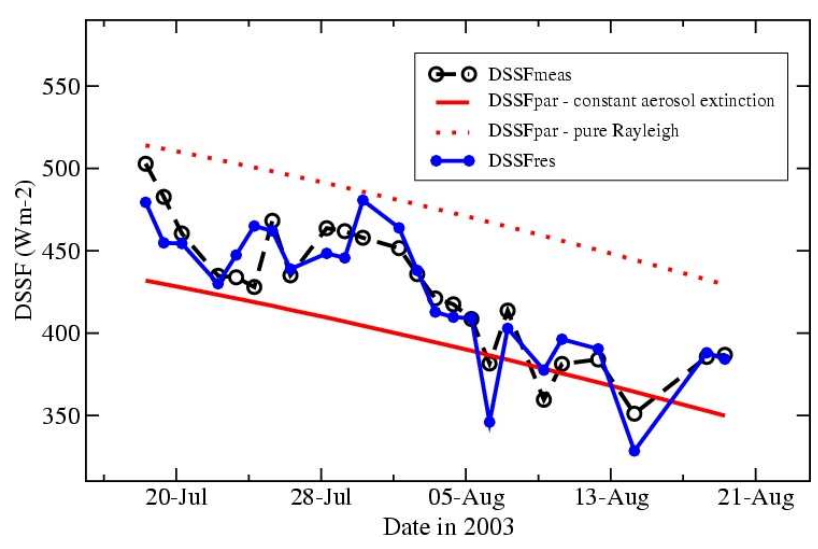

Fig. 4. Time series of $\mathrm{DSSF}_{\text {res }}, \mathrm{DSSF}_{\text {meas }}$, and $\mathrm{DSSF}_{\mathrm{par}}$ for Carpentras at 07:20 UT between 18 July and 19 August 2003. Parameterisation for pure Rayleigh is $\delta=0$, $\mathrm{W}=2.5 \mathrm{~g} \mathrm{~cm}^{-2}$, Uo3 $=300 \mathrm{DU}$, parameterisation with aerosols is $\delta=0.09, \mathrm{~W}=2.5 \mathrm{~g} \mathrm{~cm}^{-2}$, Uo3=300 DU.

the candidate $\mathrm{SAL}_{\mathrm{LUT}}$ values is kept as $\mathrm{SAL}_{\mathrm{mo}}$ (for "maximum occurrence" of SAL $\mathrm{LUT}_{\mathrm{T}}$ values), a parameter considered representative of the surface properties of the pixel. This operation is repeated for all cloud-free pixels acquired at noon during the whole month in order to provide the monthly value of $\mathrm{SAL}_{\mathrm{mo}}$. This operation also provides instantaneous value of DSSF $\mathrm{F}_{\text {res }}$ which is the average of the candidate DSSF $_{\text {LUT }}$ values (Table 2).

Second, measurements made off-nadir are processed. Simulations show that a given value of UTVR can be reproduced for several values of SAL, as long as AOT is also varied. Increasing SAL and decreasing AOT allows maintaining a constant value of UTVR. Therefore by restricting the domain of variability of SALLUT, the domain of variability of $\mathrm{AOT}_{\mathrm{LUT}}$ is also restricted. In particular the upper limit $\mathrm{SAL}_{\max }$ matches with the lower limit $\mathrm{AOT}_{\min }$. Instantaneous estimate of $\mathrm{AOT}_{\min }$ is provided by restricting SAS candidate models by the criterion: $\mathrm{SAL}_{\mathrm{LUT}}<\mathrm{SAL}_{\max }$ (Table 2). SAL ${ }_{\text {max }}$ is determined from $\mathrm{SAL}_{\mathrm{mo}}$. Because of the high anisotropy of the surface reflection, $\mathrm{SAL}_{\max }$ is made variable from morning to afternoon: $\mathrm{SAL}_{\max }=\mathrm{SAL}_{\mathrm{mo}}-0.10$ the morning, $\mathrm{SAL}_{\max }=\mathrm{SAL}_{\mathrm{mo}}-0.05$ the afternoon.

Third, $\mathrm{DSSF}_{\text {res }}$ is retrieved respecting the condition $\mathrm{AOT}_{\min }-0.1<\mathrm{AOT}_{\mathrm{LUT}}<\mathrm{AOT}_{\min }+0.2$ (Table 2). All SAS models satisfying this further condition provide values of

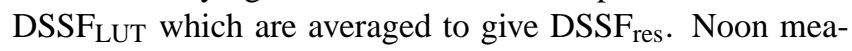
surements are not processed in this paper, and $\mathrm{SAL}_{\max }$ value is taken from Elias and Roujean (2006).

\subsection{The cloud screening}

The Institute of Climate and Meteorological Research of Karlsruhe, Germany, has developed an algorithm of cloud detection to be applied on METEOSAT-7 data, in the frame- work of the FP6/geoland objective to infer 10-days composite of 1/2-hourly surface temperature, at a spatial resolution of $10 \mathrm{~km}$, over Europe and Africa (FP6/geoland WP8316). Only clear-sky pixels are processed to deliver surface temperature, consequently the cloud mask is very strict in order to reject any pixel contaminated by cloud scattering. The cloud mask index has been validated against ground-based data sets acquired in Carpentras during the 2000 summer (Elias and Roujean, 2006). For the paper the cloud screening is based on a threshold on the temporal variability of ground-based measurements of DSSF (Sect. 4).

\section{Validation of the method}

DSSF $_{\text {res }}$ derived with the algorithm applied to METEOSAT7 data is analysed in regards to variable atmospheric situations. The validation is based on a comparison with CMP11 Kipp \& Zonen pyranometer ground-based measurements from the BSRN stations of Carpentras $\left(44^{\circ} 03^{\prime} \mathrm{N}, 05^{\circ} 02^{\prime} \mathrm{E}\right.$, $100 \mathrm{~m}$ a.s.l.) and Palaiseau $\left(48^{\circ} 42^{\prime} \mathrm{N}, 02^{\circ} 12^{\prime} \mathrm{E}, 156 \mathrm{~m}\right.$ a.s.l.). Validation of $\mathrm{AOT}_{\min }$ and $\mathrm{SAL}_{\max }$ are not the scope of the paper because they are dedicated to be used only as internal parameters of the algorithm. SAL max is estimated at 0.15 by Elias and Roujean (2006) for both locations.

The analysis considers DSSF res $_{\text {estimated each day }}$ at 07:20 UT in the July-August 2003 period, from the METEOSAT-7 slot number 14. Only cloudless scenes are retained, identified by a standard deviation of ground-based measurements of DSSF smaller than $30 \mathrm{~W} \mathrm{~m}^{-2}$ for a 30 minute interval centred on the time slot.

\subsection{Validation of the Downwelling Surface Solar radiative Flux (DSSF res)}

Figures 4 and 5 show that estimated and measured DSSF are in good agreement, demonstrating that our method is an improvement to reproduce the high temporal variability of DSSF due to changing aerosol extinction properties. As for Carpentras, the study period is 18 July-19 August 2003, with $75 \%$ of cloud-free scenes (24 cases). DSSF $\mathrm{Deas}_{\text {me }}, \mathrm{DSSF}_{\text {res }}$ and DSSF $_{\text {par }}$ are plotted in Fig. 4 in function of time. The parameterised aerosol-free reference (Eq. 1) shows that an approximate $80 \mathrm{~W} \mathrm{~m}^{-2}$ decrease in 30 days is due to a reduction in insulation (as illustrated in Fig. 2) when the solar zenith angle increases from $60^{\circ}$ to $65^{\circ}$ at the constant time of 07:20 UT. In addition, aerosols infer a strong variability during that period. $\mathrm{DSSF}_{\text {meas }}$ varies between 350 and $500 \mathrm{~W} \mathrm{~m}^{-2}$. Closest point to the spotted line occurs on 18 July indicating the minimum aerosol radiative effect during the time period. The difference between both curves increases from 19 to 23 July, reaches a secondary minimum between 28 July and $1 \mathrm{Au}-$ gust, and increases again to 6 August. The difference stays large until 14 August. 
Table 2. Successive operations to select candidate Surface-Atmosphere System models to determine DSSF res.

\begin{tabular}{|c|c|c|c|c|c|c|}
\hline $\begin{array}{l}\text { Time of } \\
\text { UTVR }_{\text {meas }}\end{array}$ & $\begin{array}{l}\text { Condition on } \\
\text { UTVR LUT }_{\text {LUT }} \\
\text { UTVR }_{\text {meas }} \text { cond }\end{array}$ & $\begin{array}{l}\text { Condition on } \\
\text { AOT }_{\text {LUT }}\end{array}$ & $\begin{array}{l}\text { Condition on } \\
\text { SAL }_{\text {LUT }}\end{array}$ & $\begin{array}{c}\text { Operation on } \\
\text { candidate values } \\
\text { DSSF }_{\text {LUT }}\end{array}$ & Result & $\begin{array}{l}\text { Time period } \\
\text { validity of the } \\
\text { retrieved parameter }\end{array}$ \\
\hline noon & $\begin{array}{c}0.9 \times \mathrm{UTVR}_{\text {meas }} \leq \\
\mathrm{UTVR}_{\mathrm{LUT}} \leq 1.1 \times \\
\mathrm{UTVR}_{\text {meas }}\end{array}$ & $<1.0$ & none & averaging & $\begin{array}{c}\text { DSSF res } \\
\text { and SAL mo }\end{array}$ & $\begin{array}{l}\text { Instantaneous } \\
\text { DSSF res \& }_{\text {monthly value }} \\
\text { of SAL }{ }_{\text {mo }}\end{array}$ \\
\hline am & $\begin{array}{c}0.9 \times \mathrm{UTVR}_{\text {meas }} \leq \\
\mathrm{UTVR}_{\mathrm{LUT}} \leq 1.1 \times \\
\mathrm{UTVR}_{\text {meas }}\end{array}$ & none & $\begin{array}{c}\mathrm{SAL}_{\mathrm{LUT}} \leq \\
\mathrm{SAL}_{\max } \text { with } \\
\mathrm{SAL}_{\max }=\mathrm{SAL}_{\mathrm{mo}} \\
-0.10\end{array}$ & I & $\mathrm{AOT}_{\min }$ & $\begin{array}{l}\text { Instantaneous } \\
\mathrm{AOT}_{\min }\end{array}$ \\
\hline am & $\begin{array}{c}0.9 \times \mathrm{UTVR}_{\text {meas }} \leq \\
\mathrm{UTVR}_{\mathrm{LUT}} \leq 1.1 \times \\
\mathrm{UTVR}_{\text {meas }}\end{array}$ & $\begin{array}{l}\mathrm{AOT}_{\min }-0.1 \\
\leq \mathrm{AOT}_{\mathrm{LUT}} \leq \\
\mathrm{AOT}_{\min }+0.2\end{array}$ & none & averaging & DSSF $_{\text {res }}$ & $\begin{array}{l}\text { Instantaneous } \\
\text { DSSF }_{\text {res }}\end{array}$ \\
\hline
\end{tabular}

$\mathrm{DSSF}_{\text {res }}$ succeeds in reproducing main variability due to aerosols (and shown by DSSF $F_{\text {meas }}$ ), as the first and second increase of the aerosol effect, and as the minimal differences on 18 July, 31 July and 1 August. In contrary, DSSF par for constant aerosol contribution $\delta=0.09$, and for $\mathrm{W}=2.5 \mathrm{gcm}^{-2}$ and Uo 3=300 DU (Eq. 1), generally underestimates DSSF meas $_{\text {. }}$ The histograms of the differences $\mathrm{DSSF}_{\text {res }}-\mathrm{DSSF}_{\text {meas }}$ and DSSF $_{\text {par }}-$ DSSF $_{\text {meas }}$ are plotted in Fig. 5a. DSSF meas $_{\text {is better }}$ reproduced by $\mathrm{DSSF}_{\mathrm{res}}$ : within $10 \mathrm{~W} \mathrm{~m}^{-2}$ in 11 cases, within $20 \mathrm{~W} \mathrm{~m}^{-2}$ (around $5 \%$ ) in 18 cases, which is $75 \%$ of the situations, and the disagreement does not exceed $40 \mathrm{~W} \mathrm{~m}^{-2}$, which is around $10 \%$ of $\mathrm{DSSF}_{\text {meas }}$. The difference between $\mathrm{DSSF}_{\text {par }}$ and $\mathrm{DSSF}_{\text {meas }}$ is included between $-10 \mathrm{~W} \mathrm{~m}^{-2}$ and $-40 \mathrm{~W} \mathrm{~m}^{-2}$ in 12 cases, and is smaller than $-50 \mathrm{~W} \mathrm{~m}^{-2}$ in 7 cases (not shown).

As for Palaiseau, the study period is 7 July31 August 2003. Cloud presence is more frequent as only $35 \%$ of the scenes are retained. SZA varies from 59 to $69^{\circ}$. The histogram of the difference $\mathrm{DSSF}_{\text {res }}-\mathrm{DSSF}_{\text {meas }}$ plotted in Fig. 5b includes Carpentras and Palaiseau. The agreement remains within $5 \%$ of $\mathrm{DSSF}_{\text {meas }}$ in $70 \%$ of the situations. In three cases (not shown), the difference is included between -60 and $-50 \mathrm{~W} \mathrm{~m}^{-2}$, which is around $20 \%$

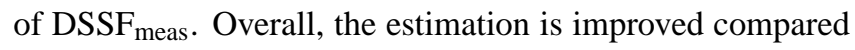
to the parameterisation for constant aerosol properties.

\subsection{Aerosol Radiative Forcing $\left(\mathrm{ARF}_{\text {res }}\right)$}

The agreement between $\mathrm{ARF}_{\text {res }}$ and $\mathrm{ARF}_{\text {meas }}$, as well as the coincidence with the variability in measured aerosol optical thickness, show that our method is sensitive to the high temporal variability of the aerosol radiative impact. Estimates $\mathrm{ARF}_{\text {res }}$ and $\mathrm{ARF}_{\text {meas }}$ for Carpentras are plotted in Fig. 6 in function of time. The $\mathrm{ARF}_{\text {res }}$ and $\mathrm{ARF}_{\text {meas }}$ estimates are calculated as the differences between a reference level on one hand, and $\mathrm{DSSF}_{\text {res }}$ and $\mathrm{DSSF}_{\text {meas }}$, respectively, on the other

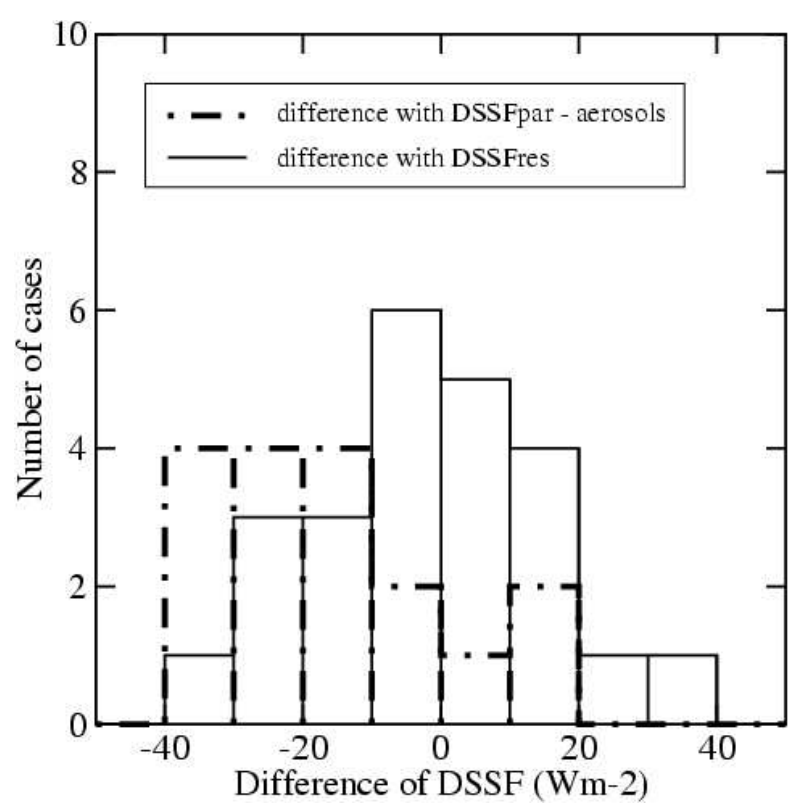

Fig. 5a. Histograms of the differences $D_{S S F}$ par $-D_{S S F}$ meas and $\mathrm{DSSF}_{\text {res }}-\mathrm{DSS}_{\text {meas }}$, in Carpentras.

hand. The reference level in Carpentras and Palaiseau is defined for zero aerosol extinction $(\delta=0)$, and for gas concentrations $\mathrm{W}=2.5 \mathrm{gcm}^{-2}$ and Uo $3=300 \mathrm{DU}$ : ARF measured in Carpentras is minimum at $11 \mathrm{~W} \mathrm{~m}^{-2}$ on 18 July 2003, and is minimum at $17 \mathrm{~W} \mathrm{~m}^{-2}$ as measured on 22 August 2003 in Palaiseau. We recognise in Fig. 6 the events already identified in Carpentras: $\mathrm{ARF}_{\text {meas }}$ and $\mathrm{ARF}_{\text {res }}$ larger than $70 \mathrm{~W} \mathrm{~m}^{-2}$ on 6,9 and 14 August and smaller than $40 \mathrm{~W} \mathrm{~m}^{-2}$ on 18 and 30 July and on 1 August.

Coincident ground-based measurements of aerosol optical thickness outline the relevance of our satellite-based method 


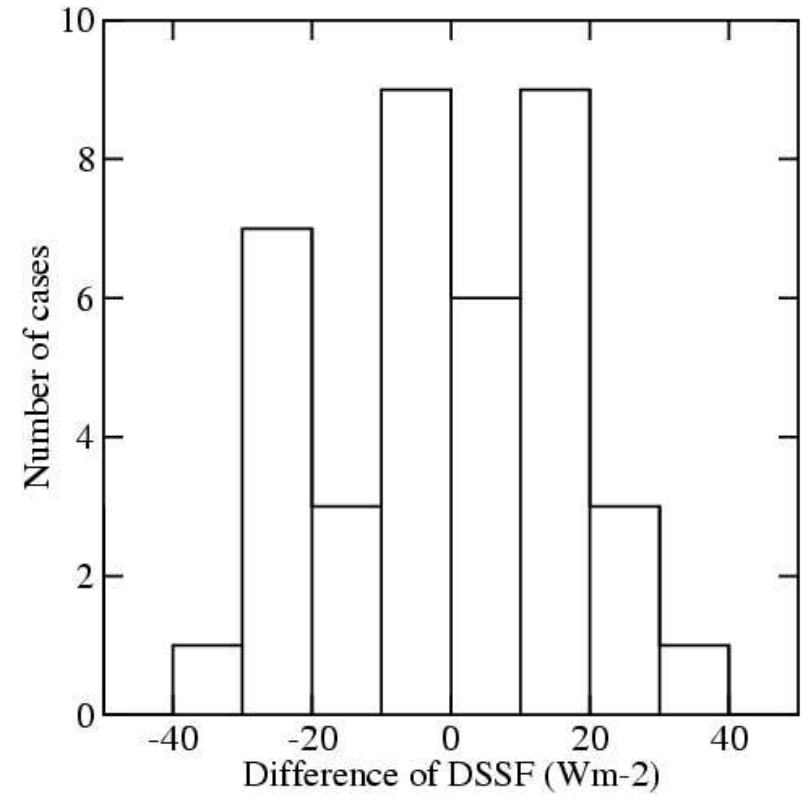

Fig. 5b. Histograms of the difference $\mathrm{DSSF}_{\text {res }}-\mathrm{DSSF}_{\text {meas }}$ for Palaiseau and Carpentras.

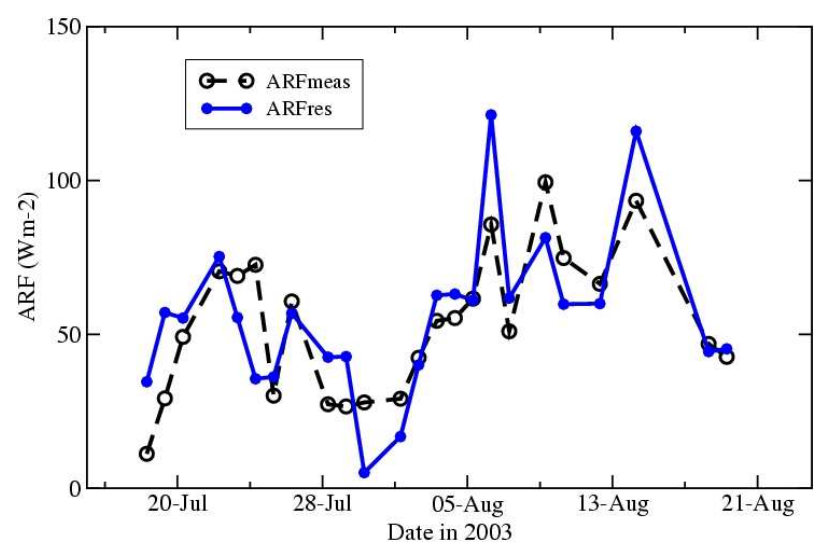

Fig. 6. Time series of the ground-based measurement and satellitebased estimate of ARF in Carpentras at 07:20 UT.

in providing the aerosol radiative impact over land. Instantaneous aerosol optical thickness measured at $440 \mathrm{~nm}$ (AOT440), at the AERONET station of Carpentras at around 07:20, is plotted in Fig. 7. AOT440 is smaller than 0.10 on 18 July, 30 July and 1 August, which correspond to minima of $\mathrm{ARF}_{\text {meas }}$, and AOT440 maxima are reached on 6 and 9 August, corresponding to $\mathrm{ARF}_{\text {meas }}$ maxima. The increase of AOT observed in Carpentras coincides with the 2003 summer heat wave and was also observed in Portugal (Elias et al., 2006), in the West Mediterranean Sea (Pace et al., 2005) and in Palaiseau.

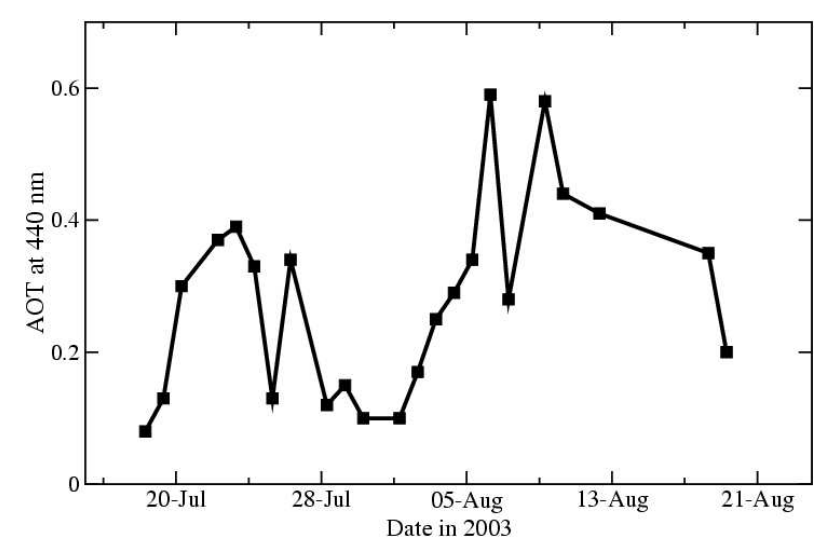

Fig. 7. Time series of the aerosol optical thickness measured at $440 \mathrm{~nm}$ at around 07:20 UT by AERONET at the station of Carpentras.

\subsection{Aerosol Radiative Forcing Efficiency (ARFE)}

Figure $8 \mathrm{a}$ and $\mathrm{b}$ shows that the algorithm is able to reproduce instantaneous and quantitative estimates of the solar energy reduction at surface level over land, in response to aerosols. $\mathrm{ARF}_{\text {res }}$ and $\mathrm{ARF}_{\text {meas }}$ are plotted in function of AOT440 for Carpentras (Fig. 8a) and for Palaiseau (Fig. 8b). Linearlyfitted values provide estimates of the aerosol radiative forcing efficiency (ARFE) relatively to AOT440. The agreement in ARFE estimate is excellent between both approaches. In Carpentras, ARFE is assessed at $143 \pm 10 \mathrm{~W} \mathrm{~m}^{-2}$ for the ground-based measurements, compared to $124 \pm 21 \mathrm{~W} \mathrm{~m}^{-2}$ for the satellite-based method. In Palaiseau, ARFE is $134 \pm 19 \mathrm{~W} \mathrm{~m}^{-2}$ for the ground-based measurements, compared to $163 \pm 53 \mathrm{~W} \mathrm{~m}^{-2}$ for the satellite-based method. The uncertainty of ARFE is the uncertainty of the slope of the regression line. The level of precision on our result is satisfying as e.g. Redemann et al. (2006) estimate an uncertainty on radiative forcing as large as 35\% in few cases, according to direct and collocated measurements of both flux and AOT.

The algorithm is validated as $\mathrm{ARF}_{\text {res }}$ and AOT are two quantities obtained in a totally independent way, but still demonstrate a correlation consistent with theory: estimations of ARFE in Carpentras and Palaiseau coincide to an accumulation-mode dominated and absorbent aerosol population (Fig. 3). This is consistent with the characteristics of the haze covering West Mediterranean, Portugal and France during the heat wave of the 2003 summer (Hodzic et al. (2006) show the transport of the forest fire emissions from Portugal to North Europe), and with urban influence in Palaiseau from nearby Paris.

\subsection{Temporal change of the Aerosol Radiative Forcing}

The major asset of the method is to be able to monitor from space the temporal variability in aerosol radiative impact. 

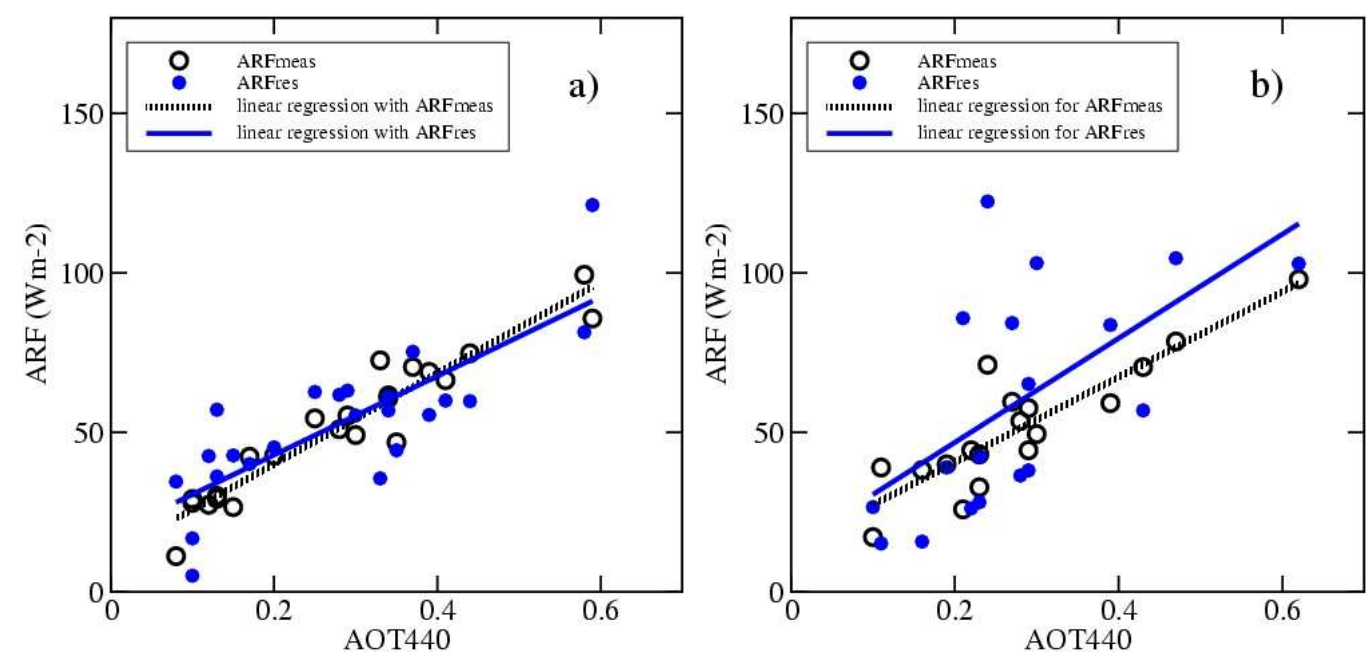

Fig. 8. Sensitivity of the aerosol radiative forcing (ARF) to the aerosol optical thickness (AOT) in (a) Carpentras and in (b) Palaiseau. ARF is calculated from DSSFmeas (open circles) and from DSSFres (filled circles). Slopes of the linear regressions give estimates of ARFE, as for Carpentras, $A R F E_{\text {meas }}=143 \pm 10 \mathrm{~W} \mathrm{~m}^{-2}$ and $\mathrm{ARFE}_{\mathrm{res}}=124 \pm 21 \mathrm{~W} \mathrm{~m}^{-2}$; and for Palaiseau, $\mathrm{ARFE}_{\mathrm{meas}}=134 \pm 19 \mathrm{~W} \mathrm{~m}^{-2}$ and ARFE $_{\mathrm{res}}=163 \pm 53 \mathrm{~W} \mathrm{~m}^{-2}$.

Satellite-based estimates of the temporal change in ARF are plotted in Fig. 9 in function of the ground-based measurement equivalent. The temporal change is calculated exclusively between 2 consecutive days. Measured changes are included between -40 and $30 \mathrm{~W} \mathrm{~m}^{-2}$ per day. The signs of both temporal changes are generally equal.

\section{Conclusions}

A method is presented leading to simultaneous estimate of the solar radiative flux reaching the land surface level (DSSF) and its temporal variability, and of the aerosol radiative forcing at land surface level (ARF), using the METEOSAT-7 visible broadband spectrum channel. The method consists in: 1) generating a Look Up Table of TOA radiance and DSSF with the 6 S radiative transfer code; 2) discriminating between aerosol and surface contributions considering the dependence of the measurement on the solar zenith angle; 3) selecting the Surface Atmosphere Systems (SAS) models able to reproduce the TOA radiance measurement, according to the inferred aerosol contribution; 4) averaging the DSSF values computed from the candidate SAS models. The validation of the method relies on the comparison between satellite-based estimates and ground-based measurements for two case studies. The measurement conditions were variable: the solar zenith angle varies from 59 to $69^{\circ}$, the aerosol types are biomass burning, urban and continental, the aerosol optical thickness varies by a factor of 6 in magnitude.

Satellite-based retrievals show a high correlation with ground-based measurements of DSSF for the two case studies considered here. Difference between the satellite-based estimates and the ground-based measurements is smaller than $20 \mathrm{~W} \mathrm{~m}^{-2}$ and $5 \%$ of the signal, for $70 \%$ of the retrievals, and smaller than $40 \mathrm{~W} \mathrm{~m}^{-2}$ for $90 \%$ of the retrievals. They are two different quantities determined on a totally independent way, but still are related according to theory. Both satellite-based estimates and ground-based measurements show a strong sensitivity to AOT, with the Aerosol Radiative Forcing Efficiency (ARFE) included between 120 and $160 \mathrm{~W} \mathrm{~m}^{-2}$ per unity of AOT440. A wide scatter of ARFE values is found in literature (Redemann et al., 2006) and more studies are necessary to define the bounds as function of the aerosol type. For example, ARFE is estimated at $200 \mathrm{~W} \mathrm{~m}^{-2}$ for 2 days of the South Africa field measurement campaign SAFARI2000 (Hansell et al., 2003). Also, Zhou et al. (2005) compute ARFE for several aerosol types using the AERONET data base. Their estimate for biomass burning in South America is $70 \mathrm{~W} \mathrm{~m}^{-2}$ and $90 \mathrm{~W} \mathrm{~m}^{-2}$ for biomass burning emissions in South Africa, per unity of AOT550.

Foreseen work will consist to delineate the domain of validity of the method concerning the aerosol types (tests for desert dust) and the surface types (tests over highly reflecting surface as desert and snow), and also to yield a validation of the estimation of the diurnal cycle of the radiative impact for different aerosol types. The major profit of the method will be to provide time series of realistic daily averages of the aerosol radiative impact in various climatic environments (continental and maritime background, urban pollution, biomass burning impacts), according to partial cloud occurrence and the measured aerosol diurnal cycle. It is included in the objectives of the FP6/geoland project to draw continental maps of DSSF with the spatial resolu- 


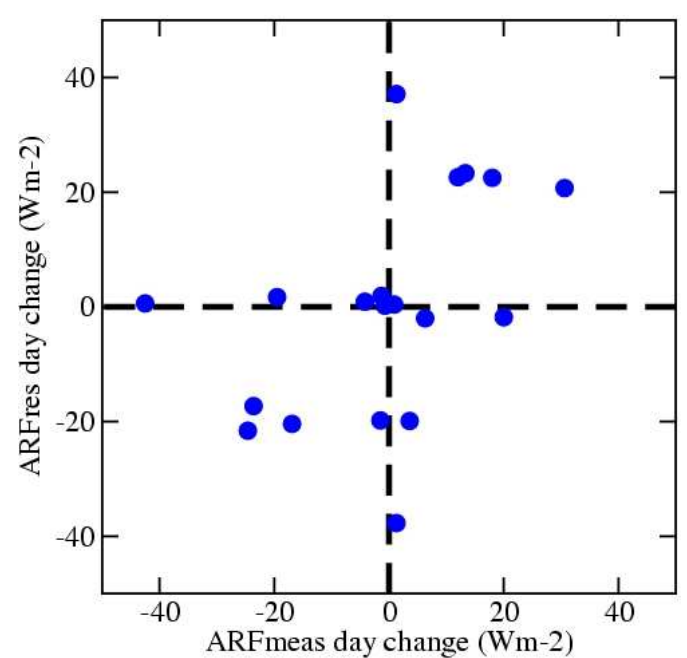

Fig. 9. Temporal change of ARF over one day in Palaiseau and Carpentras. Satellite based method against ground-based measurement estimate.

tion of $50 \mathrm{~km}$ and the temporal resolution of the hour, over the year 2000, using this method for clear-sky pixels and a parameterisation-based approach for the cloudy-sky pixels (Elias and Roujean, 2006).

This work takes part in the effort of the scientific community in relying global estimates of aerosol radiative effects upon measurements, in order to improve the climate projections, and to close the aerosol issue on climate. Our method is complementary to other methods in the objective of providing a detailed picture of the aerosol radiative effect: our method could benefit from combinations with 1) TOMS and OMI identifications of aerosol plumes characterised by high absorption properties; and with 2) identification of the aerosol type by the spatial missions as MODIS, MISR, POLDER, SCIAMACHY, in the condition the aerosol type does not change during the day.

\section{Appendix A}

$$
\begin{aligned}
K_{\text {esd }}= & 1.00011+0.034211 \cdot \cos (x) \\
& +0.00128 \cdot \sin (x) \\
& +0.000719 \cdot \cos (2 x)+7.7 E-05 \cdot \sin (2 x)
\end{aligned}
$$

where $x=6.28 \cdot(\operatorname{nod}-1) / 365$

and nod is the number of the day in the year.

$T=e^{-\frac{\delta}{\mu_{S}}}-A_{w v}\left(W / \mu_{S}\right)-A_{o z}\left(U_{\mathrm{O}_{3}} / \mu_{S}\right)-R_{r}\left(\mu_{S}\right)$ where $U_{\mathrm{O}_{3}}$ is ozone concentration, $\mathrm{W}$ is water vapour concentration, $\delta$ is an aerosol extinction parameter, and $\mu_{S}$ is the cosine of the solar zenith angle.

$$
\begin{aligned}
A_{o z}(x)= & \frac{0.02118 x}{1+0.042 x+0.000323 x^{2}}+ \\
& \frac{1.082 x}{(1+138.6 x)^{0.805}}+\frac{0.0658 x}{(1+103.6 x)^{3}} \\
A_{w v}(y)= & \frac{2.9 y}{(1+141.5 y)^{0.635}+5.925 y} \\
R_{r}\left(\mu_{S}\right)= & \frac{0.28}{1+6.43 \mu_{S}}
\end{aligned}
$$

\begin{tabular}{|c|c|}
\hline AE: & Ångström Exponent \\
\hline AERONET: & AErosol RObotic NETwork \\
\hline AOT: & Aerosol Optical Thickness \\
\hline AOT550: & AOT at $550 \mathrm{~nm}$ \\
\hline $\mathrm{AOT}_{\min }:$ & $\begin{array}{l}\text { minimum value of AOT derived from TOA } \\
\text { measurements }\end{array}$ \\
\hline ARF: & Aerosol Radiative Forcing \\
\hline $\mathrm{ARF}_{\text {res }}:$ & ARF estimated from METEOSAT-7 data set \\
\hline ARFE: & Aerosol Radiative Forcing Efficiency \\
\hline a.s.l.: & above sea level \\
\hline ASD: & Aerosol Size Distribution \\
\hline ASSA: & Aerosol Single Scattering Albedo \\
\hline ATBD: & Algorithm Theoretical Basis Document \\
\hline $\begin{array}{l}\text { BSRN: } \\
\delta:\end{array}$ & $\begin{array}{l}\text { Baseline Surface Radiation Network } \\
\text { aerosol extinction parameter }\end{array}$ \\
\hline DSSF: & Downwelling Surface Solar radiative Flux \\
\hline DSSF $_{\text {LUT: }}$ & $\begin{array}{l}\text { DSSF calculated by the } 6 \text { S radiative transfer } \\
\text { code for generating the LUT }\end{array}$ \\
\hline $\mathrm{DSSF}_{\text {meas }}$ : & ground-based measurement of DSSF \\
\hline DSSF $_{\text {par: }}$ & parameterised DSSF \\
\hline $\mathrm{DSSF}_{\text {res }}:$ & $\begin{array}{l}\text { DSSF estimated by the FP6/geoland method } \\
\text { from the METEOSAT- } 7 \text { data }\end{array}$ \\
\hline Esun: & extraterrestrial solar irradiance \\
\hline FP6: & 6th Framework Plan \\
\hline GOCART: & $\begin{array}{l}\text { GOddard Chemistry Aerosol Radiation and } \\
\text { Transport }\end{array}$ \\
\hline IPCC: & Intergovernmental Panel on Climate Change \\
\hline IRI: & \\
\hline$K_{\text {esd }}$ : & Earth-Sun distance correction factor \\
\hline & Look-Up Table \\
\hline & cosine of SZA \\
\hline
\end{tabular}

\section{List of acronyms}




\begin{tabular}{|c|c|}
\hline \multirow{3}{*}{$\begin{array}{l}\text { MODIS: } \\
\text { MISR: }\end{array}$} & MODerate Imaging Spectrometer \\
\hline & Multiangle Imaging \\
\hline & SpectroRadiometer \\
\hline POLDER: & $\begin{array}{l}\text { POLarisation and Directionality } \\
\text { of Earth Reflectance }\end{array}$ \\
\hline SAFARI2000: & South African Initiative \\
\hline SAL: & Surface ALbedo \\
\hline $\mathrm{SAL}_{\max }:$ & $\begin{array}{l}\text { FP6/geoland internal parameter } \\
\text { describing the SAL maximum in } \\
\text { the LUT }\end{array}$ \\
\hline $\mathrm{SAL}_{\mathrm{mo}}:$ & $\begin{array}{l}\text { FP6/geoland internal parameter de- } \\
\text { scribing the most occurring value of } \\
\text { SAL in candidate SAS models }\end{array}$ \\
\hline SAS: & Surface Atmosphere System \\
\hline SCIAMACHY: & $\begin{array}{l}\text { SCanning Imaging Absorption Spec- } \\
\text { troMeter for Atmospheric }\end{array}$ \\
\hline & CHartographY \\
\hline SZA: & Solar Zenith Angle \\
\hline$T:$ & atmospheric transmission \\
\hline TOA: & Top Of the Atmosphere \\
\hline TOMS: & Total Ozone Mapping Spectrometer \\
\hline$U_{\mathrm{O}_{3}}:$ & ozone concentration \\
\hline UT: & Universal Time \\
\hline UTVR: & $\begin{array}{l}\text { Upwelling TOA Visible and near in- } \\
\text { fra red Reflectance }\end{array}$ \\
\hline UTVR $_{\text {LUT: }}$ & $\begin{array}{l}\text { UTVR calculated by the } 6 \mathrm{~S} \text { radiative } \\
\text { transfer code for generating the LUT }\end{array}$ \\
\hline $\begin{array}{l}\mathrm{UTVR}_{\text {meas }} \\
W:\end{array}$ & $\begin{array}{l}\text { UTVR measured by METEOSAT-7 } \\
\text { water vapour concentration }\end{array}$ \\
\hline
\end{tabular}

Acknowledgements. BSRN and AERONET are acknowledged to provide data for the sites of Carpentras and Palaiseau, and EUMETSAT for the METEOSAT-7 data. This work was supported by the European Union 6th framework plan.

Edited by: A. Petzold

\section{References}

Chung, E. C., Ramanathan, V., Kim, D., and Podgorny, I. A.: Global anthropogenic aerosol direct forcing derived from satellite and ground-based observations, J. Geophys. Res., 110(D24), D24207, doi:10.1029/2005JD006356, 2005.

Costa, M. J. and Silva, A. M.: Aerosol radiative forcing from GEO satellite data over land surfaces, in: Remote Sensing of Clouds and the Atmosphere X, edited by: Schäfer, K.P., Comerón, A., Slusser, J. R., Picard, R. H., Carleer, M. R., and Sifakis, N.I., Proceedings of SPIE, 5979, (SPIE, Bellingham, WA), 582-589, 2005.

Elias, T. and Roujean, J. L.: ATBD Core Service biophysical Parameters - Downwelling surface Solar Radiation flux, Version 1.2, EC Proposal Reference FP-6-502871, 90 pp., http://gmes-geoland.info/CS/CSP/index.php, 2006.

Elias, T., Silva, A. M., Belo, N., Pereira, S., Formenti, P., Helas, G., and Wagner, F.: Aerosol extinction in a remote continental region of the Iberian peninsula during summer, J. Geophys. Res., 111, D14204, doi:10.1029/2005JD006610, 2006.

Gautier, C., Diak, G., and Masse, S.: A simple physical model to estimate incident solar radiation at the surface from GOES satellite data, J. Clim. Appl. Meteorol., 19, 1005-1012, 1980.

Hansell, R., Tsay, S. C., Ji, Q., Liou, K. N., and Ou, S.: Surface aerosol radiative forcing derived from collocated ground-based radiometric observations during PRIDE, SAFARI, and ACEAsia, Appl. Opt., 42, 27, 5533-5544, 2003.

Hodzic A., Vautard, R., Chepfer, H., Goloub, P., Menut, L., Chazette, P., Deuzé, J. L., Apituley, A., and Couvert, P.: Evolution of aerosol optical thickness over Europe during the August 2003 heat wave as seen from CHIMERE model simulations and POLDER data, Atmos. Chem. Phys., 6, 1853-1864, 2006, http://www.atmos-chem-phys.net/6/1853/2006/.

Holben, B. N., Tanré, D., Smirnov, A., et al.: An emerging ground-based aerosol climatology: aerosol optical depth from AERONET, J. Geophys. Res., 106, 12 067-12 097, 2001.

IPCC: Climate Change 2007: The Physical Science Basis, in: Contribution of Working Group I to the Fourth Assessment Report of the Intergovernmental Panel on Climate Change, edited by: Solomon, S., Qin, D., Manning, M., Chen, Z., Marquis, M., Averyt, K. B., Tignor, M., and Miller, H. L., Cambridge University Press, Cambridge, UK and New York, NY, USA, 996 pp, 2007.

Lacis, A. A. and Hansen, J. E.: A parameterization for the absorption of solar radiation in the Earth's atmosphere, J. Atmos. Sci., 31, 118-131, 1974.

Mc Clatchey, R. A., Fenn, R. W., Selby, J. E. A., Volz,F. E., and Garing, J. S.: Optical properties of the Atmosphere, AFCRL-TR71-0279, Enviro. Research papers, 354, L.G. HANCOM FIEL Bedford, Mass., USA, 1971.

Pace, G., Meloni, D., and Di Sarra, A.: Forest fire aerosol over the Mediterranean basin during summer 2003, J. Geophys. Res., 110, D21202, doi:10.1029/2005JD005986, 2005.

Redemann, J., Pilewskie, P., Russell, P. B., Livingston, J. M., Howard, S., Schmid, B., Pommier, J., Gore, W., Eilers, J., and Wendisch, M.: Airborne measurements of spectral direct aerosol radiative forcing in the Intercontinental chemical Transport Experiment/Intercontinental Transport and Chemical Transformation of anthropogenic pollution, 2004, J. Geophys. Res., 111, D14210, doi:10.1029/2005JD006812, 2006.

Schmetz, J.: Towards a surface radiation climatology: retrieval of downward irradiances from satellites, Atmos. Res., 23, 287-321, 1989.

Thieuleux, F., Moulin, C., Bréon, F. M., Maignan, F., Poitou, J., and Tanré, D.: Remote sensing of aerosols over the oceans using MSG/SEVIRI Imagery, Ann. Geophys., 23, 1-8, 2005, http://www.ann-geophys.net/23/1/2005/.

Vermote, E. F., Tanré, D., Deuzé, J. L., Herman, M., and Morcrette, J. J.: Second simulation of the satellite signal in the solar spectrum: An overview, Ieee Trans. Geosci. Remote Sens., 35, 675686, 1997.

Yu, H., Kaufman, Y. J., Chin, M., Feingold, G., Remer, L. A., Anderson, T. L., Balkanski, Y., Bellouin, N., Boucher, O., Christopher, S., DeCota, P., Kahn, R., Koch, D., Loeb, N., Reddy, M. S., Schulz, M., Takemura, T., and Zhou, M.: A review of measurement-based assessments of the aerosol direct radiative effect and forcing, Atmos. Chem. Phys., 6, 613-666, 2006, http://www.atmos-chem-phys.net/6/613/2006/. 
Zhou, M., Yu, H., Dickinson, R. E., Dubovik, O., and Holben, B. N.: A normalized description of the direct effect of key aerosol types on solar radiation as estimated from Aerosol Robotic Network aerosols and Moderate Resolution Imaging Spectroradiometer albedos, J. Geophys. Res., 110(D19), D19202, doi:10.1029/2005JD005909, 2005. 